\title{
Exploiting the p53 Pathway for Therapy
}

\author{
Chit Fang Cheok and David Philip Lane \\ IFOM Joint Research Laboratory and A*Star p53 Laboratory, Singapore 138648 \\ Correspondence: dplane@p53Lab.a-star.edu.sg
}

The excitement around the entry into the clinic of the first generation of p53-specific drugs has become muted as the hoped-for dramatic clinical responses have not yet been seen. However, these pioneer molecules have become exceptionally powerful tools in the analysis of the p53 pathway and, as a result, a whole spectrum of new interventions are being explored. These include entirely novel and innovative approaches to drug discovery, such as the use of exon-skipping antisense oligonucleotides and T-cell-receptor-based molecules. The extraordinary resources available to the p53 community in terms of reagents, models, and collaborative networks are generating breakthrough approaches to medicines for oncology and also for other diseases in which aberrant p53 signaling plays a role.

$\mathrm{T}^{\mathrm{h}}$ he p53 pathway is highly conserved in evoution and, yet, dispensable for the full development of a whole mouse. Its function is, thus, defined as a checkpoint or proofreader that maintains genetic integrity and protects the organism from the development of cancer. Although the core pathway components are conserved in evolution, its fine regulation is under intense evolutionary pressure, especially at the carboxy- and amino-terminal domains of p53, which vary widely in sequence among species, whereas the core DNA-binding domain is relatively invariant (Belyi et al. 2010). These variable domains interact with a large number of partner proteins that create a very complex signaling network, which involves many posttranslational modifications (Meek and Anderson 2009). This signaling network is distorted in most cancers, creating potential tumor-specific targets for therapy (see Wasylishen and Lozano 2016). Although most drug discovery efforts have focused on small molecules that disrupt the p53-Mdm2 interaction (see Wang 2016), other approaches are now gaining favor. The realization that both $\mathrm{Mdm} 2$ and Mdm4 have many $\mathrm{p} 53$-independent activities is causing a reconsideration of the significance of the Mdm2 and Mdm4 gene amplifications and high-level protein expression seen in many cancers (Dewaele et al. 2016). These proteins may actually act as driver oncoproteins whose expression should be reduced for therapeutic benefit. Similarly, the evidence that mutant p53 proteins can also act as driver oncoproteins when overexpressed has led a drive to the discovery of approaches that might block their oncogenic activity or reduce their expression (Alexandrova et al. 2015). In another strategy, molecules that bind to mutant p53 and alter its conformation such that it loses its mutant function and gains its wild-type function have been described, and one such molecule is currently in a phase 1 trial (Bykov and Wiman 2014). Increased understanding of the role that the p53 pathway plays in ischemia and neuro-

Editors: Guillermina Lozano and Arnold J. Levine

Additional Perspectives on The p53 Protein available at www.perspectivesinmedicine.org

Copyright (C) 2017 Cold Spring Harbor Laboratory Press; all rights reserved; doi: 10.1101/cshperspect.a026310

Cite this article as Cold Spring Harb Perspect Med 2017;7:a026310 
degenerative diseases is also reawakening interest in the development of p53 inhibitors, whereas the recognition of the importance of p53 in regulating metabolism shows great promise in the treatment of human metabolic syndromes, such as diabetes and obesity (Deisenroth and Zhang 2011). Very recently, the recognition of the role of p53 in controlling some bacterial infections may lead to redirecting the use of some of the current Mdm2 inhibitors and offers exciting new targets - for example, in the study of the CagA protein of Helicobacter pylori (Gonzalez et al. 2014; Siegl et al. 2014; Zaika et al. 2015). The role of the immune response in controlling cancer has become very clear with the great clinical success of the checkpoint inhibitor antibodies (Sharma and Allison 2015). Such is the extent of this revolution that the interaction and, hopefully, synergism of new anticancer drugs with the immune system will become a primary consideration in clinical development. It has also raised the question as to whether mutant p53 itself might be a target for immune recognition and therapeutic approaches. The success of synthetic lethal approaches to drug discovery highlighted by work on the poly ADP ribose polymerase (PARP) inhibitors has led to a very active pursuit of drugs that might exploit vulnerabilities created by loss of function of the p53 pathway, and a number of compounds and targets have recently been identified using this approach (Scott et al. 2015). Most successful cancer therapies rely on the use of combinations and, as such, an intense search is underway for molecules that might act in partnership with the current Mdm2 inhibitors and p53 mutant-reactive compounds that are in the clinic.

\section{IMMUNE APPROACHES TO p53 THERAPY}

Intracellular antigens are processed and derived peptides loaded onto major histocompatibility complex (MHC) molecules and presented at the cell surface for T-cell recognition. The cytotoxic $\mathrm{T}$ cells and $\mathrm{T}$ helper cells that recognize such peptide MHC complexes become activated and attack and eliminate tumor cells with great specificity and efficacy. The enormous clinical success of tumor-infiltrating lymphocyte (TIL) therapy and checkpoint therapy with antibodies to CTLA4 and PD1 has heightened interest in earlier efforts to harness the potential of T-cell responses to p53 (Wen et al. 2008). One such approach is currently in clinical trials. Here, a single-chain T-cell receptor interleukin 2 (IL2) fusion protein (Tcr-IL2) has been designed that binds to the peptide $264-272$ of p53 presented on HLA-A2 molecules at the tumor cell surface. Tcr-IL2 acts by localizing IL2 to the tumor, helping to activate a local T-cell response. The initial data show promise, and imaging studies show clear presentation of this $\mathrm{p} 53$ peptide at the surface of tumor cells. The specificity resides in the overexpression of the $\mathrm{p} 53$ protein by tumor cells as the T-cell receptor (TCR) also recognizes the wild-type p53 peptide sequence and is, therefore, not tumor specific. Currently, Tcr-IL2 looks most effective in bladder cancer and melanoma. If Tcr-IL2 has sufficient selectivity for tumor cells, it could be developed further using BiTe-like approaches (Topp et al. 2015). In this method, the TCR is coupled not to IL2, but rather to an anti-CD3 antibody that binds T cells. The BiTe molecule, thus, redirects large numbers of $\mathrm{T}$ cells to the p53-expressing tumor cells. BiTe molecules have been approved for the treatment of leukemia but carry the risk that the antigen must be really tumor specific if side effects are to be avoided. In this case, overexpression of 533 may not be enough, and it might be preferable to develop TCRs that are specific to mutant p53 peptides. Reports that such TCRs can be discovered have been published, and p53-based long peptide vaccines are in clinical trial (Speetjens et al. 2009). The understanding of the immune inhibitory microenvironment of many tumors is helping a great deal in the design of new therapeutic vaccine strategies that aim to overcome these barriers.

\section{PROGRESS ON Mdm2- AND Mdm4- TARGETING DRUGS}

Following the breakthrough proof of concept from Lubo Vassilev et al. (2004) that small molecule inhibitors of the $\mathrm{p} 53-\mathrm{Mdm} 2$ interaction could be developed, an extraordinary effort has been directed at developing such molecules by major pharmaceutical companies and promi- 
nent academic groups, and several have entered clinical trials. This is reviewed elsewhere in the literature (Wang 2016). In addition, a very novel approach using stapled peptides that inhibit both the p53-mdm 2 and the p53-Mdm4 interaction has also reached phase I and has shown good preclinical efficacy (Brown et al. 2013; Chang et al. 2013; Chen et al. 2015). As the studies have matured, a number of important caveats have emerged. The initial preclinical data are very remarkable. For example, with a single dose of the inhibitor MI-888, complete regression of the SJSA-1 xenograft was achieved with no apparent toxicity (Zhao et al.2013). However, this result is not necessarily typical of what might be expected in the clinic. Although SJSA-1 cells die when exposed to Nutlin or other human MDM2 inhibitors (HDMi), many p53 wildtype human cancer cells show a growth arrest response that is reversible rather than cell death under similar conditions of exposure (Tovar et al. 2013; Allen et al. 2014). In contrast, some normal cells are induced into apoptosis by Nutlin, with primary thymocytes being a very clear example. This brings into question the predicted therapeutic index of HDMi. An additional underappreciated factor is that, rather surprisingly, HDMi can show species specificity despite the very subtle differences in the binding site between mouse and human Mdm2 proteins. This can mean that a human xenograft will respond very well with little damage to surrounding normal mouse tissues if the small molecule preferentially blocks the human versus the mouse Mdm2 p53 interaction. This may explain why Nutlin is able to induce the accumulation of p53 in normal mouse tissue (Goh et al. 2015) but the MI-219 compound cannot (Shangary et al. 2008). Further studies using the stapled peptides, which work well across species and inhibit both the p53 Mdm2 and the p53 Mdm4 interactions may help to distinguish on-target from off-target pathologies.

\section{NEW APPROACHES TO Mdm2 AND Mdm4 INHIBITION}

A variety of new approaches to $\mathrm{Mdm} 2$ and Mdm4 inhibition has been taken in an attempt to improve the therapeutic index. In some sys- tems, Mdm4 appears as a safer target as it is amplified to high levels in only a subset of human cancers, and mouse models of genetic ablation suggest that inhibiting Mdm4 would be less toxic than inhibiting Mdm2 (Garcia et al. 2011). Although small-molecule drugs that inhibit Mdm4 p53 interactions and not Mdm2 p53 interactions have been identified, recent remarkable progress has resulted from a different approach. Studies of Mdm4 splicing patterns in tumors have shown that tumors make large amounts of full-length Mdm4 messenger RNA (mRNA), whereas in normal tissues this splice form is absent and an RNA that skips exon 6 is predominant (Dewaele et al. 2016). This RNA, known as Mdm4S, encodes a short amino-terminal fragment of Mdm4, known as Mdm4S, and the RNA is subject to nonsense-mediated decay. The Mdm4S protein is hard to detect and may be expressed at very low levels. Thus, the tumor-specific expression of high levels of full-length Mdm4 mRNA is a legitimate cancer-specific target. Indeed, using the ratio of "spliced in" to "not spliced in" RNA as a measure for Mdm4 expression, it was predicted that up to $85 \%$ of breast cancers and $57 \%$ of ovarian cancer may express high levels of full-length Mdm4 compared with normal tissues. Using an antisense morpholino oligonucleotide (ASO) designed to induce exon 6 skipping, resulting in the decreased expression of Mdm4, Dewaele et al. (2016) were able to show that this change in splicing pattern causes substantial tumor regressions. In this study, both p53-dependent and -independent mechanisms seem to be in play. Melanoma cells with wild-type p53 responded to the ASO with clear induction of $\mathrm{p} 53$ responsive genes, but melanomas with mutant p53 also showed growth delays in response to the ASO. The encouraging clarity of the measurement of spliced in versus not spliced in mRNA in tumor samples suggests that patient selection is possible and that the ASO is worthy of full clinical development.

\section{INHIBITING THE GAIN-OF-FUNCTION ACTIVITY OF MUTANT p53}

In many human cancers, the mutant $\mathrm{p} 53$ protein is expressed at high levels (Bartek et al. 1991). 
In the normal tissues of "knockin" mutant p53 mice (Terzian et al. 2008) and p53 mutant fish, expression levels of the mutant protein are low (Lee et al. 2008). When these p53 mutant fish or mice are crossed onto an Mdm2-null background, mutant p53 levels become very high and reach the levels found in human tumors (Terzian et al. 2008; Chua et al. 2015). Mutant p53 is also induced in p53 mutant animals by radiation and chemotherapy (Suh et al. 2011), but also in the case of mice treated with Nutlin (Goh et al. 2015). The conclusion is that the tumor environment inhibits p53 degradation and in normal tissues this degradation depends on Mdm2. The elevated expression of mutant p53 then becomes a potential target for therapy in the light of the large body of evidence that mutant p53 has a wide spectrum of "gain-offunction" properties that can promote survival, drug resistance, invasion, and metastasis (Sigal and Rotter 2000; Muller and Vousden 2014). Of importance for this concept is the question of "oncogene addiction." What happens to a tumor cell expressing high levels of mutant p53 if that expression is suddenly inhibited? In tissue culture models, small hairpin RNA (shRNA) knockdown of mutant p53 expression induces apoptosis (Vikhanskaya et al. 2007) and, most recently in an in vivo model, the tumor-specific inactivation of mutant p53 expression led to tumor growth inhibition apoptosis and extended survival. Direct genetic ablation of mutant p53 was engineered to remove the presence of mutant p53 in autochthonous tumors (T-cell lymphoma) (Alexandrova et al.2015). A conditional inactivatable p53R248Q (floxQ) mouse with a Rosa26CreERT2 (ERT2) knockin allele was generated, and the tumor spectrum of the progeny mirrors that of p53R248Q mutant mice. Tamoxifen treatment activates CreERT2, which deletes only the floxQ allele in the heterozygote mice, and causes widespread apoptosis and caspase 3 activation in p53R248Qflox autochthonous tumors (Alexandrova et al. 2015). This extends the survival of p53R248Qflox mice with no effect on p53-null mice, suggesting that continued expression of mutant p53 is required for tumor maintenance. In addition, deletion of HSF1, the master regulator of the heat-shock response, suppresses the oncogenicity in heterozygote mutant p53 mice but has no effect in p53-null mice. Previous studies show that the HSP90 chaperone and its positive regulator, cytosolic histone deacetylase 6 (HDAC6), are essential for the stabilization of mutant p53 protein, likely through a mechanism that involves stabilizing the aberrantly folded mutant p53 protein (Blagosklonny et al. 1996; Whitesell et al. 1998; Li et al. 2011a,b). This suggests that, perhaps, inhibiting HSP90 chaperone machinery and/ or HDAC6 will destabilize mutant p53 and reduce mutant p53-driven tumors (Blagosklonny et al. 2005). Therapeutic inhibition of HSP90 using ganetespib resulted in clear tumor reduction in p53R248Q mice, as well as in p53R172H mice, which correlates with an overall improved survival of p53R248Qflox mice with no significant effect on the $\mathrm{p} 53^{-/-}$mice, suggesting that the ganetespib specifically inhibited p53 mutant-dependent tumors (Alexandrova et al. 2015). Therapeutic inhibition of HSP90, using 17DMAG (derivative of geldanamycin) in combination with histone deacetylase inhibitors (suberoylanilide hydroxamic acid), also resulted in reduction of tumor mass in p53R172H homozygous mice and an overall improved survival (Alexandrova et al. 2015).

\section{RESTORING THE WILD-TYPE FUNCTION OF MUTANT p53}

A direct approach to restoring the function of wild-type p53 to tumor cells that contain mutant p53 is through gene editing or transplicing. The Song laboratory (He et al. 2015) used intratumoral injection of adenoviral vectors to deliver p53 trans-splicing cassettes that correct the p53R273H mutation in $\mathrm{p} 53$ by splicing in wildtype exons 8-11 using a binding domain recognition site in intron 7 . Although improvements in efficiency and delivery are required, the results showed significant tumor delay and clear reactivation of $\mathrm{p} 53$ responsive transcripts in the injected tumors. Clearly, the new CRISPRCas9 systems offer many fresh approaches, although efficiency of delivery will remain the critical issue (Hsu et al. 2014). 
A more widely used approach has been the search using both in vivo and in vitro screens for small molecules that rescue mutant p53 to wildtype function, and this field has been recently reviewed (Bykov and Wiman 2014; Selivanova 2014; Yu et al. 2014). This search was motivated by early work showing that some mutant p53 proteins could bind to p53 target sequences in the presence of small peptides, and that a temperature-sensitive mutant of p53 could be reverted through second-site mutations outside the DNA-binding domain of the protein (Hupp et al. 1993; Liu et al. 2001). At the Karolinska Institute (Stockholm, Sweden), a small collection of NSC (National Cancer Institute Developmental Therapeutics Program) compounds were screened for their ability to activate wildtype or mutant p53 leading to extensive literature on three "hit" compounds: MIRA-1, RITA, and PRIMA-1. Early results with PRIMA-1, a small-molecule cysteine-reactive species, have led to current clinical trials of its derivative APR 246 (Bykov and Wiman 2014); but, in general, the field has been fraught with difficulties of interpretation. RITA, for example, a much published reactivator of both wild-type and mutant p53, which was reported to act by binding to the amino terminus of p53 and blocking its binding to Mdm2 (Selivanova 2014), now acts as a DNA cross-linking agent that functions independently of p53 (Weilbacher et al. 2014; Wanzel et al. 2015), although MIRA-1/ NSC19630 has been shown to be an acutely toxic molecule to normal cells (Bou-Hanna et al. 2015). In contrast, APR-246 has a very benign toxicity profile and has shown some signs of clinical efficacy (Bou-Hanna et al. 2015). To what extent its mode of action is p53 dependent, however, is still a matter of some debate. Among the newer molecules reported, NSC59984 is typical of earlier work (Zhang et al. 2015). A small number of compounds are screened; the hit is a Michael acceptor and acts only at high concentrations. This compound, thus, has much in common with others and confirms the growing body of evidence that reactive cysteines and zinc coordination may be critical parameters of mutant p53 behavior. What is less clear is how these compounds work. Do they genuinely reactivate the mutant $\mathrm{p} 53$ protein or do they simply reduce its level, allowing p73 or p63 to exert p53-like effects as has been seen with shp53 treatment of mutant p53-expressing cells? A more unusual recent result identified the natural product chetomin from a screen of 56,000 compounds. Chetomin (Hiraki et al. 2015) was an outstanding hit from the 36,256 natural products screened and is active at submicromolar concentrations acting through the HSP40 chaperon family, which have been shown to be key partners in the chaperon complex that recognizes misfolded p53. We can anticipate great progress in this field in the next few years because of technology improvements. First, gene-editing methods allow us to produce very precisely engineered reporter cell systems, in which the endogenous gene can be altered by point mutation, allowing very precise isogenic screening cell lines to be made. Second, the use of CRISPR whole-genome library approaches to determine mechanisms of drug resistance (as used to establish that RITA is not p53 dependent) (Wanzel et al. 2015) will bring a new rigor to the field. Third, cellular thermal shift assay (CETSA)-based mass spectroscopy methods allow the whole proteome to be examined for targets of small-molecule drugs with unequaled precision (Martinez Molina et al. 2013; Martinez Molina and Nordlund 2015).

\section{TARGETING TUMOR VULNERABILITY IN WHICH LOSS IS GAIN}

Although mutations in the p53 gene exist in $>50 \%$ of all human cancers, therapeutic strategies targeting this large cohort of cancers are limited. An alternative approach to the selective targeting of p53 in tumors harboring p53 mutations is to exploit tumor cell vulnerabilities resulting from mutations in the p53 signaling pathway. In recent years, accumulating evidence suggests that loss of p53 either through nonsense or missense mutations could result in dependency on specific pathways that could be targeted in therapy. This could, therefore, render selective targeted toxicity to p53 mutant tumors while avoiding unspecific side effects on normal tissues. 


\section{C.F. Cheok and D.P. Lane}

The concept of synthetic lethality has been applied in the clinical setting to target BRCAdeficient tumors. PARP1 inhibitors achieved favorable initial clinical efficacy in the reduction of BRCA tumors demonstrating the first proof of concept that synthetic lethality may be an efficacious approach for cancer targeting (Farmer et al. 2005; Curtin 2012; Lord et al. 2015; Scott et al. 2015). Currently, PARP1 inhibitor olaparib is U.S. Food and Drug Administration (FDA)-approved for use in advanced ovarian cancers, whereas olaparib and other PARP1 inhibitors are in phase III trials for metastatic breast cancers for patients with BRCA1/2 mutations (National Institutes of Health Clinical Trials Registry; www.clinicaltrials.gov). Although synthetic lethality in the p53 pathway is still an experimental model, some success in initial proof of concept in in vivo mouse models and cell culture systems has driven the search for new therapeutic targets effective in eliminating p53-deficient tumors.

The unique nature of the p53-regulated response, in either promoting a proapoptotic or pro-survival outcome depending on the nature or severity of damage (Fig. 1), renders some complexity in manipulating the p53 response to benefit cytoreductive chemotherapy. It is becoming clear that the nature of the stimulus activating p53 has an impact on differentially inducing p53-dependent apoptosis or survival. This would mean that systematically screening for and identifying stresses that may promote p53-dependent survival is beneficial for elucidating pathway(s) that would severely inhibit the growth of tumors harboring p53 loss-offunction mutations. Given the complexity of the genomic background of most cancers, a robust clinical response with only p53 stratification will require the targeted pathway to be highly specific in inducing toxicity only in cells without p53 functions, or in which the mutation in the p53 gene is a driver mutation that occurs early in tumor development, which therefore results in a homogenous tumor genetic landscape. In the latter case, therapy selected for targeting p53 deficiency may then be most beneficial. For the clinical application of any p53-dependent therapy, developing methods beyond currently used immunohistochemistry

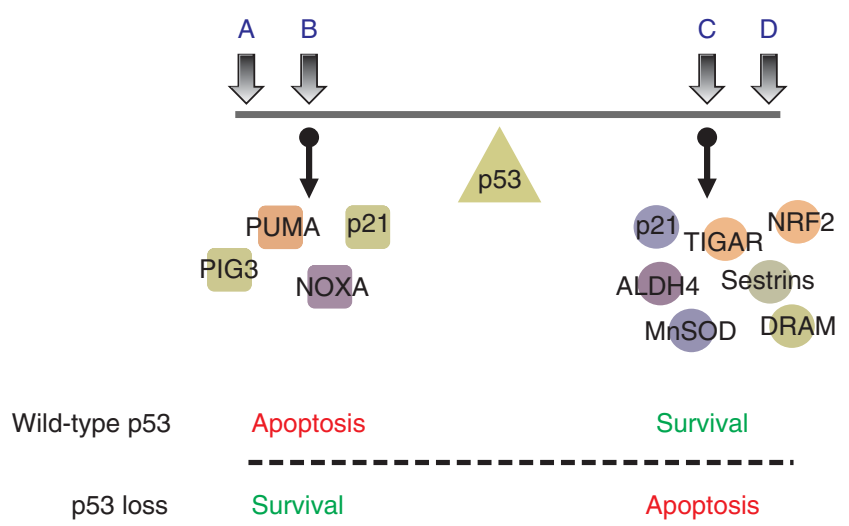

Figure 1. p53 controls the cellular response to different stress stimuli and determines cell fate. In normal cells or cancer cells harboring wild-type p53, certain cellular stresses (A and B) — for example, a high level of DNA damage or ribosomal stress, may induce p53-dependent apoptosis to eliminate severely damaged cells. In contrast, other types of stress stimuli (C and D) - for example, low levels of oxidative stress, DNA damage, or nutrient deprivation-may activate $\mathrm{p} 53$-dependent cell-survival mechanisms, which maintain homeostasis and repair for longterm cellular stability. p53-dependent transcription targets have been implicated in either proapoptotic or prosurvival mechanisms. Conversely, loss of 553 wild-type functions may lead to opposite outcomes, in which A and $\mathrm{B}$ can result in cellular resistance and survival, whereas C and D may lead to apoptosis, which is a favorable outcome for chemotherapy. Therefore, understanding the different outcomes of different stress stimuli on p53 pathway activation is useful in determining therapy for wild-type p53, as well as for p53-deficient tumor cells. 
methods is necessary to accurately determine the functional status of p53 (Robles and Harris 2010).

\section{Targeting DNA Damage and Cell-Cycle Checkpoints}

DNA damage may induce p53-dependent cellcycle arrest, apoptosis, or senescence, depending on the context and the extent and severity of damage. In response to DNA damage, p53 induces a $\mathrm{G}_{1}$-dependent cell-cycle arrest, which is primarily mediated by a $\mathrm{p} 21$-induced response, and may prevent cells from undergoing further damage in $S$ or $G_{2} / M$ phases, thus attenuating the toxicity of $\mathrm{S}$ phase or mitotic poisons (Cheok et al. 2010a,b). However, p53-deficient cells do not arrest in $\mathrm{G}_{1}$ because of a deficiency in p21-induced cell-cycle arrest. Rather, p53-deficient cells depend almost entirely on the $\mathrm{G}_{2}$ checkpoint, which provides a transient arrest, allowing cells to repair DNA damage. The $\mathrm{G}_{2}$ checkpoint is induced by ATM and ATR kinases, which are activated in response to DNA damage, and, in turn, these kinases activate CHK1/ CHK2 kinases to impose the $\mathrm{G}_{2} / \mathrm{M}$ checkpoint control (Bartek and Lukas 2003). Therefore, eliminating the $\mathrm{G}_{2}$ checkpoint through inhibiting ATR or CHK1 kinase results in a marked increase in genotoxicity in the p53-deficient cells toward radiation and different genotoxic agents, including cisplatin, campthothecin, and doxorubicin, as a consequence of the combined loss of $\mathrm{G}_{1}$ and $\mathrm{G}_{2} / \mathrm{M}$ checkpoints (Russell et al. 1995; Wang et al. 1996; Nghiem et al. 2001, 2002; Reaper et al. 2011). This concept is fully shown in different cell-based assays suggesting that the combination of ATR-dependent checkpoint inhibition and DNA-damaging agents in p53deficient cells is sufficient to induce specific toxicity in these cells (Levesque et al. 2005). Interestingly, further proof for the potency for this combination for targeting p53 deficiency is shown in a patient-derived mouse xenograft model, in which primary breast tumor or metastatic tissue in patients with triple negative breast cancer (TNBC) were engrafted into humanized mammary fat pad of NOD/SCID mice (Ma et al. 2012). The resultant TNBC human- in-mouse models with wild-type p53 or p53 mutant status were subjected to Chk1 inhibition in combination with a DNA-damaging agent. As predicted, mutation of p53 renders the patient-derived tumor to be most susceptible to the combination treatment in comparison with either drug alone or with wild-type p53 TNBC tumors treated with the same drug combination.

Similarly, genetic deletion of ATM or inhibition of ATM and ATR kinases potently sensitizes p53-deficient cells to a range of genotoxic agents (Fedier et al. 2003; Jiang et al. 2009; Toledo et al. 2011). Pharmacologic inhibition of the ATR kinase sensitizes p53-deficient cells to both replication stress inducers and DNA double-strand break induction, suggesting that the described synthetic lethality indeed derives from a checkpoint-dependent mechanism and is not specific to the nature of DNA-damaging lesions and/or replication stress (Nghiem et al. 2001, 2002; Reaper et al. 2011). Furthermore, genetic ablation of ATR in p53 mutant mice exacerbates tissue degeneration, resulting in the induction of high levels of DNA damage and lethality (Ruzankina et al. 2009). New selective inhibitors of ATR are currently being tested in phase I clinical trials. The importance of ATR kinase in maintaining genetic stability and the observed impediments of DNA replication and induction of DNA breaks following ATR depletion cast concern over the safe use of these inhibitors in the clinic. However, the observed sensitivity to ATR inhibitors in cells with p53 deficiency and oncogenic Ras suggests that the inhibitors may be more toxic to cancer cells creating a therapeutic window (Gilad et al. 2010; Murga et al. 2011; Schoppy et al. 2012). In support of this idea, hypomorphic ATR signaling (reduction to $10 \%$ of normal levels) was sufficient to kill RAS oncogene-driven tumors while minimally affecting normal bone marrow and intestinal tissues. This suggests that a complete abrogation of ATR activity is not required for tumor reduction and just a low level of ATR activity is sufficient to sustain normal cell homeostasis, therefore providing a potential therapeutic index for the action of ATR inhibitors (Schoppy et al. 2012). 
Other than ATM and ATR or CHK1/2 inhibitors, another pathway synthetically lethal with the loss of $\mathrm{G}_{1}$ checkpoint function to consider for therapeutic manipulation in p53deficient cells is the stress-activated p38 mitogen-activated protein kinase (MAPK)/(MK2) pathway (Manke et al. 2005; Reinhardt et al. 2007). The MK2 pathway is critical for cell-cycle arrest after genotoxic stress only in p53-deficient cells, suggesting that the MK2 pathway is dispensable in p53-proficient normal cells. Using an autochthonous model of NSCLC that is driven by KRAS oncogene and a Cre-inducible genetic ablation of MK2, the effects of MK2 loss on wild-type p53 and p53 knockout tumors were studied (Morandell et al. 2013). The combined deficiency in p53 and MK2 results in a synergistic response to chemotherapy resulting in an overall significant reduction in tumor burden. The apparently strong selectivity for p53-deficient background suggests that MK2 targeting may potentially be useful in combination therapy against p53-deficient tumors, with minimal side effects in normal cells.

\section{Targeting Cell Metabolism and Oxidative Stress}

p53 plays various key roles in the regulation of cellular metabolism. Under normal conditions, p53 promotes antioxidant activities by controlling the expression of various metabolic enzymes, including those that promote the pentose phosphate pathway (PPP) and, hence, increase the production of NADPH. For example, p53-dependent expression of TP53induced glycolysis and apoptosis regulator (TIGAR) limits glycolysis and, hence, enhances the production of NADPH by diverting substrates into PPP (Bensaad et al. 2006). Another example of an antioxidant role of p53 is the direct regulation of GLS2, which, apart from increasing the production of glutamate and $\alpha$-ketoglutarate, which are important intermediates in the tricarboxylic acid (TCA) cycle, also increases reduced glutathione (GSH) levels and, hence, decreases reactive oxygen species (ROS) levels (Suzuki et al. 2010). p53 also regulates a number of other important antioxidant enzymes, includ- ing MnSOD (manganese superoxide dismutase), GPx1 (glutathione peroxidase 1), and Sestrins, and protects cells against oxidative damage (Budanov et al. 2004; Hussain et al. 2004).

In a search for pathways that are necessary for tumor growth in the absence of $\mathrm{p} 53$, it was discovered that the deletion of PI5P4K $\alpha$ and $\beta$ significantly impaired tumor formation in BT474 xenograft (harboring p53 E285K mutation) and p53-deficient breast cancer cells. Significantly, deletions of both alleles of PIP4K2A and a single allele of PIP4K2B in p53-null mice results in viable mice that have an overall reduction in tumor incidence and improved tumor-free survival, suggesting that PIP4K2A and PIP4K2B play important roles in mediating metabolic changes in p53-deficient cells undergoing oncogenic transformation, because normal tissues are completely viable. It was suggested that PI5P4Ks are important for limiting ROS-dependent cellular damage by suppressing the high levels of PI-5-P, especially in p53-deficient cells. It was further suggested that high levels of PI5P4Ks are important for maintaining high glucose metabolism in p53-deficient cells, thereby reducing the rates of ROS production from oxidative phosphorylation. Therefore, by targeting PIP54Ks, one could achieve synthetic lethal elimination of p53-deficient tumors while achieving low toxicity for normal tissues.

Other synthetic lethal approaches that are dependent on metabolic stress and ROS generation in p53-deficient cells include the deprivation of the amino acid serine. Serine withdrawal in p53-deficient cells results in oxidative stress and cell death. Wild-type cells, however, respond to serine starvation by inducing a p53/ p21-dependent cell-cycle arrest and suppress glycolysis, but induce a higher rate of oxidative phosphorylation with a favorable outcome of ATP production. Similarly, glutamine deprivation also activates p53-dependent gene transcription of a subunit of PP2A $(B 55 \alpha)$ in a ROS-dependent manner and drives p53-dependent metabolic adaptation to low glutamine conditions for cell survival (Gwinn and SweetCordero 2013). More direct pharmacologic manipulation of the cellular metabolic states using AMPK activators (AICAR) or Metformin, 
which triggers AMPK activation, likely simulates conditions of nutrient deprivation. AICAR and Metformin cause cell death in p53-deficient cells but not in wild-type cells (Buzzai et al. 2007; Ben Sahra et al. 2010). Consequently, glucose starvation also sensitizes p53-deficient cells toward apoptosis (Jiang et al. 2015). The protective mechanism of p53 against cell death under nutrient-starved conditions can be partly explained by the activation of autophagy and fatty acid $\beta$-oxidation. In fact, p53 regulates many genes that promote the fatty acid $\beta$-oxidation pathway, including CPT1C (carnitine palmitoyltransferase 1C), ACAD11 (acyl-CoA dehydrogenase), LPIN1 (lipin 1), MCD (malonyl CoA decarboxylase), GAMT (guanidinoacetate methyl transferase), and PANK1 (pantothenate kinase 1) (Ide et al. 2009; Assaily et al. 2011; Bohlig et al. 2011; Liu et al. 2014; Jiang et al. 2015). Under conditions of glucose deprivation, fatty acid oxidation provides a source of energy and ATP generation through OXPHOS (oxidative phosphorylation) in p53-proficient cells to maintain viability (Kruiswijk et al. 2015). p53deficient cells, however, are more vulnerable to energy fluctuations as a result of being less able to use other alternative energy sources, which provides an alternative route for targeting the reprogrammed metabolic network in p53-deficient tumors.

\section{SYNTHETIC LETHALITY WITH GAIN- OF-MUTANT p53 FUNCTION}

It is clear that hotspot mutations of p53 can lead to gain of function, and this is commonly associated with the metastasis of cancers (see Shetzer et al. 2016). This led to predictions that targeting mutant p53 gain-of-function effects may be beneficial for the reduction of cancers harboring mutant $\mathrm{p} 53$.

The dependence of mutant p53-driven invasive responses of tumors on epidermal growth factor receptor (EGFR) and MET signaling suggest that mutant p53-expressing tumors may be more responsive to anti-EGFR or anti-MET therapy (Adorno et al. 2009; Sauer et al. 2010; Wang et al. 2013). Transcriptional changes in cell-surface receptors, such as EGFR and MET, are driven indirectly by mutant $\mathrm{p} 53$ via its interaction with p63 and p73 transcription factors. In addition, mutant p53 can promote the enhanced recycling of these cell-surface receptors, thus enhancing the oncogenic signaling resulting in increased invasion and metastasis (Muller et al. 2009, 2013). Interestingly, a clinical study that examined the response of 64 metastatic colorectal cancer patients (who are refractory to irinotecan) to cetuximab (anti-EGFR)-based chemotherapy found that TP53 mutations were significantly associated with controlled disease (CD) and higher time-to-progression of disease (Oden-Gangloff et al. 2009). This study suggests that TP53 mutations are predictive of cetuximab sensitivity, and stratification using p53 genetic status could predict responders to cetuximabbased chemotherapy.

The fastest route to the clinical translation of synthetic lethal strategies to p53 deficiency may possibly lie in using available FDA-approved molecules that could target specific pathways. A recent example is the inhibition of PDGFR $\beta$ by the FDA-approved agent imatinib that, as a single agent, led to the striking reduction of tumor metastases in a mouse model of pancreatic ductal adenocarcinoma, which expresses p53R172H (Weissmueller et al. 2014). PDGFR $\beta$ was found to be selectively up-regulated by mutant p53, and mutant p53 expression was required to maintain the prometastatic phenotype of the murine model of pancreatic cancer, which is a highly metastatic cancer that is frequently linked with p53 mutations (Morton et al. 2010; Waddell et al. 2015). Besides, simvastatin, a clinically approved blood cholesterol-lowering drug, blocks proliferation and the invasive phenotype of mutant p53 breast cancer cells and reduces tumor growth in mice implanted with mutant p53 xenografts (Freed-Pastor et al. 2012). Transcriptomics profiling shows that the mevalonate pathway is up-regulated in mutant p53 cancer cells and suggests that targeting this pathway using statins may be a viable strategy for reducing p53 mutant tumor invasiveness and proliferation (Freed-Pastor et al. 2012).

Targeting tumor vulnerabilities in cancers harboring p53 mutations provides exciting and diverse possibilities for new, targeted ther- 
apies that may provide broad cancer spectrum cures. The current challenge lies in carefully and accurately diagnosing the genetic status of p53 in patients to use it as a guide for the stratification of patients to receive therapy against wild-type p53-containing tumors or tumors harboring p53 mutations. This will also aid in the clinical determination of the effectiveness of these targeted therapies based on the p53 pathway.

\section{CONCLUSION}

The compelling data on the frequency of p53 mutations in human cancer have led to a huge international effort to understand the function of this most important tumor suppressor. The growing data that support the idea that mutant p53 acts as an oncogene and that our common radiation and chemotherapy regimes induce both mutant (bad!) and wild-type (good!) p53 expression lends a new urgency to the quest for p53-based selective therapies. Cutting-edge technologies in immunology, genetics, and chemistry are being used by a field that is always open to innovation. Although early trials of p53based drugs have failed to show remarkable success, there is little doubt that the sustained effort of the community has already led to remarkable advances in basic understanding and is poised to soon achieve the clinical impact that has inspired us all in this long and remarkable journey. The search is, therefore, on to find approaches that can down-regulate the expression of the mutant p53 protein in tumors. A number of such molecules have been described, including the combination of HSP90 inhibitors with histone deacetylase inhibitors, which have been shown to act by destabilizing mutant p53 despite quite pelitropic action (Li et al. 2011a,b). Other molecules with such activity include many compounds, such as NSC 59984 (Zhang et al. 2015) and chemotin (Hiraki et al. 2015) that are claimed to "rescue" mutant p53 by converting it to wild-type activity. This down-regulation of a rescued molecule is anticipated if the rescued mutant p53 activates transcription of Mdm2 leading to p53 degradation. Improvements in antisense oligo design and delivery mean that this approach can also be extended in the future. As described above, rescuing mutant p53 to wild-type function should both eliminate the gain of function of mutant p53 and restore the tumor suppressor function of wild-type p53.

\section{REFERENCES}

${ }^{*}$ Reference is also in this collection.

Adorno M, Cordenonsi M, Montagner M, Dupont S, Wong C, Hann B, Solari A, Bobisse S, Rondina MB, Guzzardo V, et al. 2009. A mutant-p53/Smad complex opposes p63 to empower TGF $\beta$-induced metastasis. Cell 137: 87-98.

Alexandrova EM, Yallowitz AR, Li D, Xu S, Schulz R, Proia DA, Lozano G, Dobbelstein M, Moll UM. 2015. Improving survival by exploiting tumour dependence on stabilized mutant p53 for treatment. Nature 523: 352-356.

Allen MA, Andrysik Z, Dengler VL, Mellert HS, Guarnieri A, Freeman JA, Sullivan KD, Galbraith MD, Luo X, Kraus WL, et al. 2014. Global analysis of p53-regulated transcription identifies its direct targets and unexpected regulatory mechanisms. eLife 3: e02200.

Assaily W, Rubinger DA, Wheaton K, Lin Y, Ma W, Xuan W, Brown-Endres L, Tsuchihara K, Mak TW, Benchimol S. 2011. ROS-mediated p53 induction of Lpin 1 regulates fatty acid oxidation in response to nutritional stress. Mol Cell 44: 491-501.

Bartek J, Lukas J. 2003. Chk1 and Chk2 kinases in checkpoint control and cancer. Cancer Cell 3: 421-429.

Bartek J, Bartkova J, Vojtesek B, Staskova Z, Lukas J, Rejthar A, Kovarik J, Midgley CA, Gannon JV, Lane DP. 1991. Aberrant expression of the p53 oncoprotein is a common feature of a wide spectrum of human malignancies. Oncogene 6: 1699-1703.

Belyi VA, Ak P, Markert E, Wang H, Hu W, Puzio-Kuter A, Levine AJ. 2010. The origins and evolution of the p53 family of genes. Cold Spring Harb Perspect Biol 2: a001198.

Bensaad K, Tsuruta A, Selak MA, Vidal MN, Nakano K, Bartrons R, Gottlieb E, Vousden KH. 2006. TIGAR, a p53-inducible regulator of glycolysis and apoptosis. Cell 126: $107-120$.

Ben Sahra I, Laurent K, Giuliano S, Larbret F, Ponzio G, Gounon P, Le Marchand-Brustel Y, Giorgetti-Peraldi S, Cormont M, Bertolotto C, et al. 2010. Targeting cancer cell metabolism: The combination of metformin and 2-deoxyglucose induces p53-dependent apoptosis in prostate cancer cells. Cancer Res 70: 2465-2475.

Blagosklonny MV, Toretsky J, Bohen S, Neckers L. 1996. Mutant conformation of p53 translated in vitro or in vivo requires functional HSP90. Proc Natl Acad Sci 93: 8379-8383.

Blagosklonny MV, Trostel S, Kayastha G, Demidenko ZN, Vassilev LT, Romanova LY, Bates S, Fojo T. 2005. Depletion of mutant p53 and cytotoxicity of histone deacetylase inhibitors. Cancer Res 65: 7386-7392.

Bohlig L, Friedrich M, Engeland K. 2011. p53 activates the PANK1/miRNA-107 gene leading to downregulation of 
CDK6 and p130 cell cycle proteins. Nucleic Acids Res 39: 440-453.

Bou-Hanna C, Jarry A, Lode L, Schmitz I, Schulze-Osthoff K, Kury S, Bezieau S, Mosnier JF, Laboisse CL. 2015. Acute cytotoxicity of MIRA-1/NSC19630, a mutant p53-reactivating small molecule, against human normal and cancer cells via a caspase-9-dependent apoptosis. Cancer Lett 359: 211-217.

Brown CJ, Quah ST, Jong J, Goh AM, Chiam PC, Khoo KH, Choong ML, Lee MA, Yurlova L, Zolghadr K, et al. 2013. Stapled peptides with improved potency and specificity that activate p53. ACS Chem Biol 8: 506-512.

Budanov AV, Sablina AA, Feinstein E, Koonin EV, Chumakov PM. 2004. Regeneration of peroxiredoxins by p53-regulated sestrins, homologs of bacterial AhpD. Science 304: 596-600.

Buzzai M, Jones RG, Amaravadi RK, Lum JJ, DeBerardinis RJ, Zhao F, Viollet B, Thompson CB. 2007. Systemic treatment with the antidiabetic drug metformin selectively impairs p53-deficient tumor cell growth. Cancer Res 67: 6745-6752.

Bykov VJ, Wiman KG. 2014. Mutant p53 reactivation by small molecules makes its way to the clinic. FEBS Lett 588: $2622-2627$.

Chang YS, Graves B, Guerlavais V, Tovar C, Packman K, To KH, Olson KA, Kesavan K, Gangurde P, Mukherjee A, et al. 2013. Stapled $\alpha$-helical peptide drug development: A potent dual inhibitor of MDM2 and MDMX for p53-dependent cancer therapy. Proc Natl Acad Sci 110: E3445-E3454.

Chen X, Tai L, Gao J, Qian J, Zhang M, Li B, Xie C, Lu L, Lu W, Lu W. 2015. A stapled peptide antagonist of MDM2 carried by polymeric micelles sensitizes glioblastoma to temozolomide treatment through p53 activation. J Control Release 218: 29-35.

Cheok CF, Kua N, Kaldis P, Lane DP. 2010a. Combination of nutlin-3 and VX-680 selectively targets p53 mutant cells with reversible effects on cells expressing wild-type p53. Cell Death Differ 17: 1486-1500.

Cheok CF, Verma CS, Baselga J, Lane DP. 2010b. Translating p53 into the clinic. Nat Rev Clin Oncol 8: 25-37.

Chua JS, Liew HP, Guo L, Lane DP. 2015. Tumor-specific signaling to $\mathrm{p} 53$ is mimicked by $\mathrm{Mdm} 2$ inactivation in zebrafish: Insights from $m d m 2$ and $m d m 4$ mutant zebrafish. Oncogene 34: 5933-5941.

Curtin NJ. 2012. DNA repair dysregulation from cancer driver to therapeutic target. Nat Rev Cancer 12: 801-817.

Deisenroth C, Zhang Y. 2011. The ribosomal proteinMdm2-p53 pathway and energy metabolism: Bridging the gap between feast and famine. Genes Cancer 2: 392403.

Dewaele M, Tabaglio T, Willekens K, Bezzi M, Teo SX, Low DH, Koh CM, Rambow F, Fiers M, Rogiers A, et al. 2016. Antisense oligonucleotide-mediated MDM4 exon 6 skipping impairs tumor growth. J Clin Invest 126: 68-84.

Farmer H, McCabe N, Lord CJ, Tutt AN, Johnson DA, Richardson TB, Santarosa M, Dillon KJ, Hickson I, Knights C, et al. 2005. Targeting the DNA repair defect in BRCA mutant cells as a therapeutic strategy. Nature 434: 917921.
Fedier A, Schlamminger M, Schwarz VA, Haller U, Howell SB, Fink D. 2003. Loss of atm sensitises $p 53$-deficient cells to topoisomerase poisons and antimetabolites. Ann Oncol 14: 938-945.

Freed-Pastor WA, Mizuno H, Zhao X, Langerod A, Moon SH, Rodriguez-Barrueco R, Barsotti A, Chicas A, Li W, Polotskaia A, et al. 2012. Mutant p53 disrupts mammary tissue architecture via the mevalonate pathway. Cell 148: 244-258.

Garcia D, Warr MR, Martins CP, Brown Swigart L, Passegue E, Evan GI. 2011. Validation of MdmX as a therapeutic target for reactivating p53 in tumors. Genes Dev 25: $1746-1757$.

Gilad O, Nabet BY, Ragland RL, Schoppy DW, Smith KD, Durham AC, Brown EJ. 2010. Combining ATR suppression with oncogenic Ras synergistically increases genomic instability, causing synthetic lethality or tumorigenesis in a dosage-dependent manner. Cancer Res 70: 9693-9702.

Goh AM, Xue Y, Leushacke M, Li L, Wong JS, Chiam PC, Rahmat SA, Mann MB, Mann KM, Barker N, et al. 2015. Mutant p53 accumulates in cycling and proliferating cells in the normal tissues of p53 R172H mutant mice. Oncotarget 6: $17968-17980$.

Gonzalez E, Rother M, Kerr MC, Al-Zeer MA, Abu-Lubad M, Kessler M, Brinkmann V, Loewer A, Meyer TF. 2014. Chlamydia infection depends on a functional MDM2p53 axis. Nat Commun 5: 5201.

Gwinn D, Sweet-Cordero EA. 2013. The phosphatase PP2A links glutamine to the tumor suppressor p53. Mol Cell 50: $157-158$.

He X, Liao J, Liu F, Yan J, Yan J, Shang H, Dou Q, Chang Y, Lin J, Song Y. 2015. Functional repair of p53 mutation in colorectal cancer cells using trans-splicing. Oncotarget 6: 2034-2045.

Hiraki M, Hwang SY, Cao S, Ramadhar TR, Byun S, Yoon KW, Lee JH, Chu K, Gurkar AU, Kolev V, et al. 2015. Small-molecule reactivation of mutant p53 to wildtype-like p53 through the p53-Hsp40 regulatory axis. Chem Biol 22: 1206-1216.

Hsu PD, Lander ES, Zhang F. 2014. Development and applications of CRISPR-Cas9 for genome engineering. Cell 157: $1262-1278$

Hupp TR, Meek DW, Midgley CA, Lane DP. 1993. Activation of the cryptic DNA binding function of mutant forms of p53. Nucleic Acids Res 21: 3167-3174.

Hussain SP, Amstad P, He P, Robles A, Lupold S, Kaneko I, Ichimiya M, Sengupta S, Mechanic L, Okamura S, et al. 2004. p53-induced up-regulation of MnSOD and GPx but not catalase increases oxidative stress and apoptosis. Cancer Res 64: 2350-2356.

Ide T, Brown-Endres L, Chu K, Ongusaha PP, Ohtsuka T, El-Deiry WS, Aaronson SA, Lee SW. 2009. GAMT, a p53inducible modulator of apoptosis, is critical for the adaptive response to nutrient stress. Mol Cell 36: 379-392.

Jiang H, Reinhardt HC, Bartkova J, Tommiska J, Blomqvist C, Nevanlinna H, Bartek J, Yaffe MB, Hemann MT. 2009. The combined status of ATM and p53 link tumor development with therapeutic response. Genes Dev 23: 18951909.

Jiang D, LaGory EL, Kenzelmann Broz D, Bieging KT, Brady CA, Link N, Abrams JM, Giaccia AJ, Attardi LD. 2015. 
Analysis of p53 transactivation domain mutants reveals Acad11 as a metabolic target important for $\mathrm{p} 53$ pro-survival function. Cell Rep 10: 1096-1109.

Kruiswijk F, Labuschagne CF, Vousden KH. 2015. p53 in survival, death and metabolic health: A lifeguard with a license to kill. Nat Rev Mol Cell Biol 16: 393-405.

Lee KC, Goh WL, Xu M, Kua N, Lunny D, Wong JS, Coomber D, Vojtesek B, Lane EB, Lane DP. 2008. Detection of the 553 response in zebrafish embryos using new monoclonal antibodies. Oncogene 27: 629-640.

Levesque AA, Kohn EA, Bresnick E, Eastman A. 2005. Distinct roles for p53 transactivation and repression in preventing UCN-01-mediated abrogation of DNA damage-induced arrest at $S$ and $G_{2}$ cell cycle checkpoints. Oncogene 24: 3786-3796.

Li D, Marchenko ND, Moll UM. 2011a. SAHA shows preferential cytotoxicity in mutant p53 cancer cells by destabilizing mutant p53 through inhibition of the HDAC6Hsp90 chaperone axis. Cell Death Differ 18: 1904-1913.

Li D, Marchenko ND, Schulz R, Fischer V, Velasco-Hernandez T, Talos F, Moll UM. 2011b. Functional inactivation of endogenous MDM2 and CHIP by HSP 90 causes aberrant stabilization of mutant p53 in human cancer cells. Mol Cancer Res 9: 577-588.

Liu WL, Midgley C, Stephen C, Saville M, Lane DP. 2001. Biological significance of a small highly conserved region in the $\mathrm{N}$ terminus of the p53 tumour suppressor protein. J Mol Biol 313: 711-731.

Liu Y, He Y, Jin A, Tikunov AP, Zhou L, Tollini LA, Leslie P, Kim TH, Li LO, Coleman RA, et al. 2014. Ribosomal protein-Mdm2-p53 pathway coordinates nutrient stress with lipid metabolism by regulating MCD and promoting fatty acid oxidation. Proc Natl Acad Sci 111: E2414E2422.

Lord CJ, Tutt AN, Ashworth A. 2015. Synthetic lethality and cancer therapy: Lessons learned from the development of PARP inhibitors. Annu Rev Med 66: 455-470.

Ma CX, Cai S, Li S, Ryan CE, Guo Z, SchaiffWT, Lin L, Hoog J, Goiffon RJ, Prat A, et al. 2012. Targeting Chk1 in p53deficient triple-negative breast cancer is therapeutically beneficial in human-in-mouse tumor models. J Clin Invest 122: 1541-1552.

Manke IA, Nguyen A, Lim D, Stewart MQ, Elia AE, Yaffe MB. 2005. MAPKAP kinase-2 is a cell cycle checkpoint kinase that regulates the $\mathrm{G}_{2} / \mathrm{M}$ transition and $\mathrm{S}$ phase progression in response to UV irradiation. Mol Cell 17: 37-48.

Martinez Molina D, Nordlund P. 2015. The cellular thermal shift assay: A novel biophysical assay for in situ drug target engagement and mechanistic biomarker studies. Annu Rev Pharmacol Toxicol 56: 141-161.

Martinez Molina D, Jafari R, Ignatushchenko M, Seki T, Larsson EA, Dan C, Sreekumar L, Cao Y, Nordlund P. 2013. Monitoring drug target engagement in cells and tissues using the cellular thermal shift assay. Science 341: 84-87.

Meek DW, Anderson CW. 2009. Posttranslational modification of p53: Cooperative integrators of function. Cold Spring Harb Perspect Biol 1: a000950.

Morandell S, Reinhardt HC, Cannell IG, Kim JS, Ruf DM, Mitra T, Couvillon AD, Jacks T, Yaffe MB. 2013. A reversible gene-targeting strategy identifies synthetic lethal in- teractions between MK2 and p53 in the DNA damage response in vivo. Cell Rep 5: 868-877.

Morton JP, Timpson P, Karim SA, Ridgway RA, Athineos D, Doyle B, Jamieson NB, Oien KA, Lowy AM, Brunton VG, et al. 2010. Mutant p53 drives metastasis and overcomes growth arrest/senescence in pancreatic cancer. Proc Natl Acad Sci 107: 246-251.

Muller PA, Vousden KH. 2014. Mutant p53 in cancer: New functions and therapeutic opportunities. Cancer Cell 25: 304-317.

Muller PA, Caswell PT, Doyle B, Iwanicki MP, Tan EH, Karim S, Lukashchuk N, Gillespie DA, Ludwig RL, Gosselin P, et al. 2009. Mutant p53 drives invasion by promoting integrin recycling. Cell 139: 1327-1341.

Muller PA, Trinidad AG, Timpson P, Morton JP, Zanivan S, van den Berghe PV, Nixon C, Karim SA, Caswell PT, Noll JE, et al. 2013. Mutant p53 enhances MET trafficking and signalling to drive cell scattering and invasion. Oncogene 32: $1252-1265$.

Murga M, Campaner S, Lopez-Contreras AJ, Toledo LI, Soria R, Montana MF, D'Artista L, Schleker T, Guerra C, Garcia E, et al. 2011. Exploiting oncogene-induced replicative stress for the selective killing of Myc-driven tumors. Nat Struct Mol Biol 18: 1331-1335.

Nghiem P, Park PK, Kim Y, Vaziri C, Schreiber SL. 2001. ATR inhibition selectively sensitizes $G_{1}$ checkpoint-deficient cells to lethal premature chromatin condensation. Proc Natl Acad Sci 98: 9092-9097.

Nghiem P, Park PK, Kim Y, YS, Desai BN, Schreiber SL. 2002. ATR is not required for p53 activation but synergizes with p53 in the replication checkpoint. J Biol Chem 277: $4428-4434$.

Oden-Gangloff A, Di Fiore F, Bibeau F, Lamy A, Bougeard G, Charbonnier F, Blanchard F, Tougeron D, Ychou M, Boissiere F, et al. 2009. TP53 mutations predict disease control in metastatic colorectal cancer treated with cetuximabbased chemotherapy. Br J Cancer 100: 1330-1335.

Reaper PM, Griffiths MR, Long JM, Charrier JD, Maccormick S, Charlton PA, Golec JM, Pollard JR. 2011. Selective killing of ATM- or p53-deficient cancer cells through inhibition of ATR. Nat Chem Biol 7: 428-430.

Reinhardt HC, Aslanian AS, Lees JA, Yaffe MB. 2007. p53deficient cells rely on ATM- and ATR-mediated checkpoint signaling through the $\mathrm{p} 38 \mathrm{MAPK} / \mathrm{MK} 2$ pathway for survival after DNA damage. Cancer Cell 11: 175-189.

Robles AI, Harris CC. 2010. Clinical outcomes and correlates of TP53 mutations and cancer. Cold Spring Harb Perspect Biol 2: a001016.

Russell KJ, Wiens LW, Demers GW, Galloway DA, Plon SE, Groudine M. 1995. Abrogation of the $G_{2}$ checkpoint results in differential radiosensitization of $G_{1}$ checkpoint-deficient and $\mathrm{G}_{1}$ checkpoint-competent cells. Cancer Res 55: 1639-1642.

Ruzankina Y, Schoppy DW, Asare A, Clark CE, Vonderheide $\mathrm{RH}$, Brown EJ. 2009. Tissue regenerative delays and synthetic lethality in adult mice after combined deletion of Atr and Trp53. Nat Genet 41: 1144-1149.

Sauer L, Gitenay D, Vo C, Baron VT. 2010. Mutant p53 initiates a feedback loop that involves Egr-1/EGF receptor/ERK in prostate cancer cells. Oncogene 29: 26282637. 
Schoppy DW, Ragland RL, Gilad O, Shastri N, Peters AA, Murga M, Fernandez-Capetillo O, Diehl JA, Brown EJ. 2012. Oncogenic stress sensitizes murine cancers to hypomorphic suppression of ATR. J Clin Invest 122: 241-252.

Scott CL, Swisher EM, Kaufmann SH. 2015. Poly (ADPribose) polymerase inhibitors: Recent advances and future development. J Clin Oncol 33: 1397-1406.

Selivanova G. 2014. Wild type p53 reactivation: From lab bench to clinic. FEBS Lett 588: 2628-2638.

Shangary S, Qin D, McEachern D, Liu M, Miller RS, Qiu S, Nikolovska-Coleska Z, Ding K, Wang G, Chen J, et al. 2008. Temporal activation of p53 by a specific MDM2 inhibitor is selectively toxic to tumors and leads to complete tumor growth inhibition. Proc Natl Acad Sci 105: 3933-3938.

Sharma P, Allison JP. 2015. Immune checkpoint targeting in cancer therapy: Toward combination strategies with $\mathrm{cu}-$ rative potential. Cell 161: 205-214.

* Shetzer Y, Molchadsky A, Rotter V. 2016. Oncogenic mutant p53 gain of function nourishes the vicious cycle of tumor development and cancer stem-cell formation. Cold Spring Harb Perspect Med doi: 10.1101/cshperspect .a026203.

Siegl C, Prusty BK, Karunakaran K, Wischhusen J, Rudel T. 2014. Tumor suppressor p53 alters host cell metabolism to limit Chlamydia trachomatis infection. Cell Rep 9: 918-929.

Sigal A, Rotter V. 2000. Oncogenic mutations of the p53 tumor suppressor: The demons of the guardian of the genome. Cancer Res 60: 6788-6793.

Speetjens FM, Kuppen PJ, Welters MJ, Essahsah F, Voet van den Brink AM, Lantrua MG, Valentijn AR, Oostendorp J, Fathers LM, Nijman HW, et al. 2009. Induction of p53specific immunity by a 533 synthetic long peptide vaccine in patients treated for metastatic colorectal cancer. Clin Cancer Res 15: 1086-1095.

Suh YA, Post SM, Elizondo-Fraire AC, Maccio DR, Jackson JG, El-Naggar AK, Van Pelt C, Terzian T, Lozano G. 2011. Multiple stress signals activate mutant $\mathrm{p} 53$ in vivo. Cancer Res 71: 7168-7175.

Suzuki S, Tanaka T, Poyurovsky MV, Nagano H, Mayama T, Ohkubo S, Lokshin M, Hosokawa H, Nakayama T, Suzuki Y, et al. 2010. Phosphate-activated glutaminase (GLS2), a p53-inducible regulator of glutamine metabolism and reactive oxygen species. Proc Natl Acad Sci 107: 7461-7466.

Terzian T, Suh YA, Iwakuma T, Post SM, Neumann M, Lang GA, Van Pelt CS, Lozano G. 2008. The inherent instability of mutant $\mathrm{p} 53$ is alleviated by Mdm2 or p16INK4a loss. Genes Dev 22: 1337-1344.

Toledo LI, Murga M, Zur R, Soria R, Rodriguez A, Martinez S, Oyarzabal J, Pastor J, Bischoff JR, Fernandez-Capetillo O. 2011. A cell-based screen identifies ATR inhibitors with synthetic lethal properties for cancer-associated mutations. Nat Struct Mol Biol 18: 721-727.

Topp MS, Gokbuget N, Stein AS, Zugmaier G, O’Brien S, Bargou RC, Dombret H, Fielding AK, Heffner L, Larson RA, et al. 2015. Safety and activity of blinatumomab for adult patients with relapsed or refractory B-precursor acute lymphoblastic leukaemia: A multi- centre, single-arm, phase 2 study. Lancet Oncol 16: $57-66$.

Tovar C, Graves B, Packman K, Filipovic Z, Higgins B, Xia M, Tardell C, Garrido R, Lee E, Kolinsky K, et al. 2013. MDM2 small-molecule antagonist RG7112 activates p53 signaling and regresses human tumors in preclinical cancer models. Cancer Res 73: 2587-2597.

Vassilev LT, Vu BT, Graves B, Carvajal D, Podlaski F, Filipovic Z, Kong N, Kammlott U, Lukacs C, Klein C, et al. 2004. In vivo activation of the $\mathrm{p} 53$ pathway by small-molecule antagonists of MDM2. Science 303: 844-848.

Vikhanskaya F, Lee MK, Mazzoletti M, Broggini M, Sabapathy K. 2007. Cancer-derived p53 mutants suppress p53-target gene expression-Potential mechanism for gain of function of mutant p53. Nucleic Acids Res 35: 2093-2104.

Waddell N, Pajic M, Patch AM, Chang DK, Kassahn KS, Bailey P, Johns AL, Miller D, Nones K, Quek K, et al. 2015. Whole genomes redefine the mutational landscape of pancreatic cancer. Nature 518: 495-501.

Wang Q, Fan S, Eastman A, Worland PJ, Sausville EA, O'Connor PM. 1996. UCN-01: A potent abrogator of $\mathrm{G}_{2}$ checkpoint function in cancer cells with disrupted p53. J Natl Cancer Inst 88: 956-965.

Wang W, Cheng B, Miao L, Mei Y, Wu M. 2013. Mutant p53$\mathrm{R} 273 \mathrm{H}$ gains new function in sustained activation of EGFR signaling via suppressing miR-27a expression. Cell Death Dis 4: e574.

* Wang S, Zhao Y, Aguilar A, Bernard D, Yang C-Y. 2016. Targeting the MDM2-p53 protein-protein interaction for new cancer therapy: Progress and challenges. Cold Spring Harb Perspect Med doi: 10.1101/cshperspect. a026245.

Wanzel M, Vischedyk JB, Gittler MP, Gremke N, Seiz JR, Hefter M, Noack M, Savai R, Mernberger M, Charles JP, et al. 2015. CRISPR-Cas9-based target validation for p53-reactivating model compounds. Nat Chem Biol 12: $22-28$.

* Wasylishen AR, Lozano G. 2016. Attenuating the p53 pathway in human cancers: Many means to the same end. Cold Spring Harb Perspect Med doi: 10.1101/cshperspect .a026211.

Weilbacher A, Gutekunst M, Oren M, Aulitzky WE, van der Kuip H. 2014. RITA can induce cell death in p53-defective cells independently of p53 function via activation of JNK/SAPK and p38. Cell Death Dis 5: e1318.

Weissmueller S, Manchado E, Saborowski M, Morris JPT, Wagenblast E, Davis CA, Moon SH, Pfister NT, Tschaharganeh DF, Kitzing T, et al. 2014. Mutant p53 drives pancreatic cancer metastasis through cell-autonomous PDGF receptor $\beta$ signaling. Cell 157: 382-394.

Wen J, Zhu X, Liu B, You L, Kong L, Lee HI, Han KP, Wong JL, Rhode PR, Wong HC. 2008. Targeting activity of a TCR/IL-2 fusion protein against established tumors. Cancer Immunol Immunother 57: 1781-1794.

Whitesell L, Sutphin PD, Pulcini EJ, Martinez JD, Cook PH. 1998. The physical association of multiple molecular chaperone proteins with mutant $\mathrm{p} 53$ is altered by geldanamycin, an hsp90-binding agent. Mol Cell Biol 18: 1517-1524. 


\section{C.F. Cheok and D.P. Lane}

Yu X, Narayanan S, Vazquez A, Carpizo DR. 2014. Small molecule compounds targeting the p53 pathway: Are we finally making progress? Apoptosis 19: 1055-1068.

Zaika AI, Wei J, Noto JM, Peek RM. 2015. Microbial regulation of p53 tumor suppressor. PLoS Pathog 11: e1005099.

Zhang S, Zhou L, Hong B, van den Heuvel AP, Prabhu VV, Warfel NA, Kline CL, Dicker DT, Kopelovich L, El-Deiry WS. 2015. Small-molecule NSC59984 restores p53 path- way signaling and antitumor effects against colorectal cancer via p73 activation and degradation of mutant p53. Cancer Res 75: 3842-3852.

Zhao Y, Yu S, Sun W, Liu L, Lu J, McEachern D, Shargary S, Bernard D, Li X, Zhao T, et al. 2013. A potent smallmolecule inhibitor of the MDM2-p53 interaction (MI888) achieved complete and durable tumor regression in mice. J Med Chem 56: 5553-5561. 


\title{
$\&_{\mathrm{CSH}}^{\infty} \&$ Cold Spring Harbor



\section{Exploiting the p53 Pathway for Therapy}

\author{
Chit Fang Cheok and David Philip Lane
}

Cold Spring Harb Perspect Med 2017; doi: 10.1101/cshperspect.a026310 originally published online February 13, 2017

\section{Subject Collection The p53 Protein}

Targeting the MDM2-p53 Protein-Protein Interaction for New Cancer Therapy: Progress and Challenges

Shaomeng Wang, Yujun Zhao, Angelo Aguilar, et al.

Structural Evolution and Dynamics of the p53

Proteins

Giovanni Chillemi, Sebastian Kehrloesser,

Francesca Bernassola, et al.

Exploiting the p53 Pathway for Therapy

Chit Fang Cheok and David Philip Lane

The Regulation of Cellular Functions by the p53 Protein: Cellular Senescence

Crystal A. Tonnessen-Murray, Guillermina Lozano and James G. Jackson

The Transactivation Domains of the p53 Protein Nitin Raj and Laura D. Attardi

The Evolution of the Ribosomal Protein-MDM2p53 Pathway

Chad Deisenroth, Derek A. Franklin and Yanping Zhang

Somatic TP53 Mutations in the Era of Genome

Sequencing

Pierre Hainaut and Gerd P. Pfeifer

The Paradox of p53: What, How, and Why? Yael Aylon and Moshe Oren
Control of Cellular Aging, Tissue Function, and Cancer by p53 Downstream of Telomeres Caitlin M. Roake and Steven E. Artandi

Inherited TP53 Mutations and the Li -Fraumeni Syndrome

Tanya Guha and David Malkin

TP53 Mutations in Hypodiploid Acute Lymphoblastic Leukemia

Evan Q. Comeaux and Charles G. Mullighan

Transcriptional Regulation by Wild-Type and

Cancer-Related Mutant Forms of p53

Neil T. Pfister and Carol Prives

The Inherited p53 Mutation in the Brazilian Population

Maria Isabel Achatz and Gerard P. Zambetti

TP53 Mutations in Breast and Ovarian Cancer Laxmi Silwal-Pandit, Anita Langerød and Anne-Lise Børresen-Dale

p53 and the Carcinogenicity of Chronic Inflammation

Andrei V. Gudkov and Elena A. Komarova

Oncogenic Mutant p53 Gain of Function

Nourishes the Vicious Cycle of Tumor

Development and Cancer Stem-Cell Formation

Yoav Shetzer, Alina Molchadsky and Varda Rotter

For additional articles in this collection, see http://perspectivesinmedicine.cshlp.org/cgi/collection/ 